\title{
1. Introduction: broadening the scope and dynamics of entrepreneurship research in Europe
}

\section{Paula Kyrö and Alain Fayolle}

This book continues the discourse on the dynamics of entrepreneurship research set in motion in the first book in this series, European Research in Entrepreneurship (Fayolle et al., 2005). At that time our aim was to identify and elaborate the emergence of a European position in the entrepreneurship debate and to see what kind of a profile the European research might have. The positive response to that book indicated that European research does indeed have its specifics, which merit further research.

In our introduction, 'The entrepreneurship debate in Europe: a matter of history and culture', we anticipated that the dialogue between Europe and, for example, Asia will intensify in the future, challenging European research and efforts to enhance its entrepreneurial and innovative culture. This challenge is a reality today. For example the Chinese government has now taken a strategic decision to develop an innovation-based country by 2020 by integrating entrepreneurship into its education, developmental activities and research (Wang Xingsun, 2007). There is also a lot to do to catch up with the USA in this respect. Only the new EU member states, Latvia, Lithuania and Poland score better than the USA in the desirability of self-employment (European Commission, 2007). Inside Europe the assessment of the Total Entrepreneurial Activity (TEA) Index signals that the countries ranked high in innovativeness still have entrepreneurial activity below the European average, for example France, Finland and Estonia. These striking differences and contradictions in entrepreneurial activities, readiness and innovativeness within European countries and the proactive attitude and activities of European competitors impose a demand for a better understanding of the complex dynamics between entrepreneurship, environment and education. The spirit and pervasive theme of this book follow this new emerging and complex understanding of entrepreneurship and take advantage of the opportunities it offers to revitalize the ideas of the European historical roots of entrepreneurship. Each chapter investigates some aspect of the 
relationship between entrepreneurship and environment, and thus enhances this complex dialogue.

In this landscape our book will outline the different aspects of this dynamics exemplifying the expanding European dialogue between entrepreneurship, environment and education. Its 14 chapters, including the introduction and the conclusion, represent different disciplines, nationalities and approaches. Altogether they bring us findings from 13 countries, and 28 researchers from 21 universities and research institutions. By bringing these together we hope to define the shape, dimensions and horizon of the multidisciplinary landscape for others to learn from and explore further.

The first part of the book illustrates how the dynamics between entrepreneurship and environment has expanded and diversified, the second part further explores the dynamics between entrepreneurship and education, and the third part elaborates how this simultaneously culture-specific but globally oriented approach, changes the activities and developmental needs of the firms. Thus the book offers a perspective through which to understand the importance of European cultural roots within the international entrepreneurship research. It introduces both comparative chapters and chapters with specific cultural contexts to investigate what kind of aspects we might share in Europe and what aspects are culture-specific.

In this introduction we try to describe how entrepreneurship research has spread in a variety of directions as interactions with environment, educational systems and organizations. As anticipated in our last book, it has gained a more extended cultural and networking view in its efforts to contribute to renewing society. This has come a long way from the specificities of an individual entrepreneur and the basic functions of the small firm, opening up a new and complex landscape for researchers. This landscape is briefly developed in each section of our introduction, before the presentation of the chapters themselves from all these three different but interrelated spheres.

\section{DIALOGUE BETWEEN ENTREPRENEURSHIP AND ENVIRONMENT}

The dialogue between entrepreneurship and environment has been expanded and broadened both in policy documents and research. It is among the key factors in the EU innovation strategy, which emphasizes the importance of the creation of an entrepreneurial culture by fostering the right mindset, entrepreneurship skills and awareness of its career opportunity as an essential part of European competitiveness (Commission of the 
European Communities, 2006). This broad cultural approach has also been reinforced in entrepreneurship research. It brings together multidisciplinary research, for example, from economics, sociology, management, marketing, strategy, education and geography, and links organizational, regional and national cultures to systems, structures and networks. It also includes public spheres of entrepreneurship research and provides new concepts for understanding their dynamics and interrelationships (Bjerke and Dalhammar, 2006). Besides the interplay between economics, businesses, firms and regional and national prosperity, entrepreneurship research has attached itself to broader concepts such as active citizenship, education systems, curriculum development and democracy.

This complexity has not been received without criticism. Some researchers feel that expanding entrepreneurship research to so many aspects, structures and processes of society dissolves its borders and blurs its identity. On the other hand there are others who ask how cultural changes and research of its dynamics are possible by isolating phenomena out of context and the dynamics that mould these contexts. These contradictory opinions are ingredients in the current research and mould the conceptualization of entrepreneurship. For example, Dalhammar argues here for the expanded approach and introduces us to a new concept of public entrepreneurship, which is not restricted to the economic sphere. As he defines it, "The term "public" emphasizes public space, that is, the space that concerns all citizens and that is neither private nor official' (Dalhammar, this volume, p. 47)

Part I of the book, 'The dynamics between entrepreneurship and environment' contains four chapters. These four chapters together colour the landscape of interrelationships between environment and entrepreneurship, its structures, systems and processes that attract European scholars today. They all seek to expand the concepts and dimensions of research to complex processes, and combine company, local and national activities with the global problems we face today.

Chapter 2, 'New elements for the analysis of entrepreneurial structure', written by Cuevas and Carrasco of the University of Seville, analyses the quality perspective on entrepreneurial structure. Their interest comprehends the whole economic system in which the entrepreneurial activity is located. Thus they develop further the general ideas of Schumpeter on entrepreneurial innovation. The authors argue that their new concept of functional dependency within the scope of 'New Economic Geography' is quite close to the 'value chain' approach. Their findings from 400 enterprises in Andalusia in southern Spain open further two main research fields. On the one hand, it is possible to develop a comparative analysis among regions in order to identify the profile of those entrepreneurial clusters that contribute most/least to economic growth. On the other hand, 
their new concept may be useful in analysis of the role of SMEs in global value chains for different activity sectors. This chapter describes how the firms' and regions' growth is not only dependent on quantity but essentially on quality issues embedded in the structures of an economic system. These features are not only region-specific but reflect shared aspects of global value chains.

In Chapter 3, 'Micro-macro paradoxes of entrepreneurship', Søgaard of Denmark suggests that a strong micro focus in entrepreneurship research leads us to neglect macro-level explanations for entrepreneurship and to abstract it from the wider systems effects of stimulating or hampering entrepreneurship. Søgaard points out that the macro perspective is not an aggregation of micros but a far more complex social process. More specifically, he investigates this problem by analysing from the 2004 articles on Entrepreneurship and Regional Development to what extent entrepreneurship research does (or does not) address relevant 'systems effects' of entrepreneurial activity. The author concludes that a tendency to ignore the wider social implications of entrepreneurial activities should be taken seriously by any researcher wanting to see entrepreneurship as a fully-fledged member of the social sciences. To go further in that direction, he suggests, requires a commitment to understanding for the sake of understanding and more or less remembering the ideals of the classical Humboldt University.

Going further in that direction, in Chapter 4, 'New initiatives to revitalize society: public entrepreneurship in the south of Sweden', Dalhammar of the University of Malmö investigates public entrepreneurship that conceptualizes activities mainly belonging to society and not restricted to the economic sphere. This public entrepreneurship relates to the growing theoretical school of social entrepreneurship. The term 'public' emphasizes public space that concerns all citizens and that is neither private nor official. Together with Bjerke the author suggests that public entrepreneurship can be conceptualized by a social mission of creating something that others can use or benefit from. In this field social change theory can bring into entrepreneurship research an approach where change is seen as a structured process in which it may be possible to identify a specific direction or tendency. It can also lead us to investigate the changes that affect norms, values, behaviour, cultural meanings, and social relationships (Scott and Marshall, 2005).

As his case studies Dalhammar uses examples of new initiatives that deal with unemployment for marginalized people in urban areas, Job Emergency in Malmö and Business Pool in Landskrona. The results indicate how such initiatives can contribute to social change. These examples, which are in a specific cultural context containing at the same time commonalities and differences, provide ideas about how to increase the collaborative 
responsibility of dealing with huge immigration problems all over the world. As the author argues, public entrepreneurship is crucial as a means of revitalizing a city or a region, and even whole societies. In this context public entrepreneurship is a new concept that reflects the society of today and the society of tomorrow, helping us to critically study and evaluate public entrepreneurship initiatives and analyse their role in creating social value and contributing to social change.

Chapter 5 in Part I, 'Developing characteristics of an intrapreneurshipsupportive culture' draws our attention to the intersection of national, professional and corporate culture. The research group of Menzel, Krauss, Ulijn and Weggeman from the Department of Technology Management in the Technological University of Eindhoven in the Netherlands identifies the conditions required in order to make intrapreneurship occur in the large established firms and other organizations. Using Hofstede's (2001) theory and terminology about national cultures, they develop a sixdimensional description of a culture conducive to intrapreneurship. Aggregating 329 quotations from 97 publications they identify 24 culturally-bound factors that provide Hofstede's dimensions with a new open system dimension. By this addition they believe it is possible to make a distinction between intrapreneurship-supportive and non-supportive cultures and thus improve the innovativeness and competitiveness of large firms and organizations. This chapter indicates how complex and multidimensional the cultural processes are and how professional and corporate cultures are intertwined in the processes enhancing entrepreneurial behaviours and practices.

\section{DIALOGUE BETWEEN ENTREPRENEURSHIP AND EDUCATION}

A new emerging discourse in entrepreneurship education addresses its attention to education systems, curriculum development and pedagogy. This branch of research regards learning entrepreneurial and enterprising readiness as a lifelong process which assumes multidisciplinary research and expertise throughout the educational system (Kyrö and Carrier, 2005). These points of departure provide a new direction and still unexplored landscape for entrepreneurship research. Education is both society's medium for adopting its ideas of a good life, and a process of preparation for the students of the future (Bowen, 1981). The European Commission Report in 2002 recommended acknowledging the importance of entrepreneurship teaching in the national curriculum as well as in the curricula for each level of the educational system as one of the key qualitative indicators 
for entrepreneurship education (European Commission, 2002). However, little is actually known in entrepreneurship research about the complex interrelationships between education systems, curriculum development and pedagogy.

In research this challenges us to combine expertise both from education and business-related disciplines, and to cross the borders of different educational levels. Perhaps the lack of such research is due to the fact that education and economics in Europe are historically regarded as two different spheres, and comprehensive and university-level education especially have emphasized the ideal of the civilized human being as a contradiction to the market actor. Still today entrepreneurship education in most cases is regarded as business education and many countries even today focus mainly on adult education, as Hytti's and Seikkula-Leino's chapters in this book demonstrate. To overcome these problems and contradictions we have to be able to open up the conceptual dialogue between these two spheres and consider their cultural differences. We also need to differentiate the dominating Anglo-American discourse from the continental European discourse to understand the impact of these differences and to benefit from their advantages (cf. Kyrö, 2006).

As Seikkula-Leino argues in Chapter 9, the curriculum is the most important document in the education system. It expresses the wishes and needs of a society and shows how to adopt these wishes in practice. It indicates what relevant skills should be achieved through education and what kind of education programmes should be provided (Bobbitt, 2004, p. 11). Thus changing the curriculum is about making changes in societies. Therefore values as well as ideological and political objectives drive these changes. The current policy proposal to integrate entrepreneurship education into the curricula of all EU member states represents such an ideological and political objective. The curriculum legitimates the idea of the 'right' knowledge and proceeding, being thus a powerful document that creates the basis for educational movements. A curriculum reform also expresses social pressures, such as developing equality and adjusting education to meet the needs of labour development (Flouris and Pasias, 2003). A curriculum also defines subject matter, pedagogical development and assessment, thus guiding what and how to teach and learn (cf. Flouris and Pasias, 2003).

The differences in developing entrepreneurship by mainstreaming it throughout curricula at all levels of education show considerable variation among European countries. For example Austria, Denmark, Finland, Iceland, Luxemburg, Norway, Spain and Sweden have already included entrepreneurship education throughout their curricula (European Commission, 2002; 2004). Hytti's comparative study in this book indicates how differently 
policy-makers understand the content and pedagogy of entrepreneurship education in different countries. It also explains how this understanding leads to different curricular decisions with direct bearing on practice. However, it might also represent cultural differences or confusion or lack of consensus about how entrepreneurial and enterprising education should be integrated into curricula and education systems.

Part II of the book, 'The dynamics between entrepreneurship and education', continues the discussion on the interrelationships of society and entrepreneurship, now from an education perspective. It explores the dimensions of integrating entrepreneurship into governmental support and education systems. Thus it draws our attention to the various aspects of education, their similarities and differences, thereby also imparting some ideas on how to be more successful in these processes.

Chapter 6, 'University entrepreneurship and government support schemes', starts this discussion by positioning spin-off processes to the larger international and national settings and structures. The authors, Rasmussen, Borch and Sørheim of the Bodø Graduate School of Business, argue for the need to reform the commercialization of research, both by changes in the academic system and in the instruments for research funding and by setting up separate structures to support such activities. They claim that due to the complexity of entrepreneurial activity in academic settings there is a need for tailor-made instruments which should also be adapted to the national agendas. However, they claim that few studies have investigated how these government schemes are designed and implemented. Their findings from a comparative study of government programmes in Canada, Finland, Ireland, Norway, Scotland and Sweden pave the way for conclusions regarding the kind of rationale behind the differences in the support schemes between these countries and the different ways of structuring the support programmes at government, university and project levels. This interplay sets the scene for the processes that provide innovations in education systems and further for the programmes and abilities needed to enhance them.

In Chapter 7, 'Enterprise education in different cultural settings and at different school levels', Hytti continues the educational discourse by claiming that as enterprise education does not take place in a vacuum, the entrepreneurial culture and environment of a given region, country or a particular school needs to be taken into consideration when planning the enterprise education programme. She suggests that since European countries have different entrepreneurial cultures, these differences should also be reflected in the enterprise education programmes and curricular structure. The comparative analyses of the differences in enterprise education programmes run in five European countries, Austria, Finland, Ireland, 
Norway and UK identify these differences in the national approaches and the content of the programmes. In some countries especially the focus is solely on business abilities and there seems to be a lack of programmes at an earlier stage (kindergarten, primary schools), while only few programmes focus on building awareness and on supporting entrepreneurial behaviour. The author suggests that the bridges between entrepreneurship and education (pedagogy) should be stronger in order to make enterprise education as much about the process as about the subject. If the focus is only on developing the skills of potential and future entrepreneurs, these programmes will only cater for the needs of a small minority.

Chapter 8, 'Assessment and promotion of entrepreneurial initiative and attitudes towards entrepreneurship: the case of Estonia' by Venesaar and Jakobson, aptly exemplifies the situation in a country that only recently laid down new guidelines for entrepreneurship development and education from 2007 to 2013. This government's understanding of entrepreneurship follows the broad approach and highlights cultural and educational aspects. The authors report a situation of initiative and attitudes just before this programme was launched. Their first survey contains a sample of 1000 Estonians aged 16 to 64 and the second survey of 443 bachelor's and master's students. These findings give all of us some interesting ideas about the factors behind the high scores of Estonia, the similarities and differences between entrepreneurs and potential entrepreneurs, students and non-students. As Hytti suggests, they also lay the foundations for developing country-specific government actions and education.

Chapter 9 continues this discourse with the case of Finland, where enterprise education has a strong non-business focus compared to other countries in Hytti's study. Under the title 'Advancing entrepreneurship education in Finnish basic education: the prospects for developing local curricula', Seikkula-Leino introduces a partnership model based on curriculum theories. She suggests that using a partnership model in curriculum reform might help to better understand the complex dynamics between different partners involved. She further investigates through this model how the National Core Curriculum for Basic Education established in 2004 has succeeded locally. According to this, all municipalities are required to offer entrepreneurship education, at least after 2006. The survey of teachers, principals, curriculum coordinators, directors of education and cultural services departments, trades ombudsmen and representatives of local entrepreneurs (N 478) was conducted in spring 2005. Despite the numerous difficulties listed by respondents, one third of those in teaching were going to implement more entrepreneurship education in 
their future daily work. Despite this result, partners know relatively little or nothing about entrepreneurship education and the partnership model has not been as successful as expected. It seems that the curriculum that is taught and the curriculum that is learned can only develop if it is a vivid document that is able to be changed and shared by all partners involved in the process.

\section{DIALOGUE BETWEEN ENTREPRENEURSHIP AND ORGANIZATION}

Many businesses are faced by the growing competitive intensity of a complex and changing environment, and while their very existence depends on strongly established structures, they cannot remain in a precarious status quo. In order to survive, innovation is a key factor. Corporate entrepreneurship or intrapreneurship is precisely one business tactic adopted by these companies to bring new elements into their system without creating chaos. It consists in encouraging the emergence of new activities that bring about growth. These can take the form of internal ventures; organizations created or 'started up' within an already existing business frame.

Reproducing entrepreneurial attitudes and behaviours within existing companies and institutions therefore appears, at least theoretically, as an effective antidote to inertia and lack of innovation within these organizations (Stevenson and Jarillo, 1990; Fayolle and Basso, forthcoming). In practice, however, the difficulties experienced by the organizations that have tried to develop these behaviours and attitudes reveal another aspect of the phenomenon: the existence of contradictions and paradoxes linked to the combination of conflicting perspectives that result in counter-productive tensions. Current research in the field of corporate entrepreneurship study, among other topics, underlines the influence of key variables, such as culture for instance (see Chapter 5), on the firm's entrepreneurial behaviours. Moreover, the researcher is more and more trying to open the black box of organization in which appear the counter-productive contradictions and paradoxes between a traditional bureaucratic behaviour and a more entrepreneurial one.

In Part III of the book, 'The dynamics between entrepreneurship and small businesses', each of the four chapters investigates the landscape of small firm competitiveness from different perspectives. They contemplate the broadening horizon of small firms and organizations requiring methodological and theoretical renewal, ability and capability to adapt to and compete in the global landscape and find ideas for sustaining competitiveness in the future. 
In Chapter 10, 'An empirical taxonomy of start-up firms' growth trajectories', the Belgian research group of Diambeidou, François, Gailly, Verleysen and Wertz seeks to develop a methodological solution for investigating the dynamic approach to new firm growth processes. They analyse the initial growth trajectories of 741 Belgian firms using their new applied mathematical method. Their results question the relevance of uniform quantitative approaches to studying growth processes and suggest that new firm growth is neither a continuous nor idiosyncratic process. It can be adequately described through a limited number of typical growth trajectories that can be identified in a systematic way.

In Chapter 11, 'Linking entrepreneurial orientation and dynamic capabilities: research issues and alternative models', Grande suggests that the interface between entrepreneurial orientation and dynamic capabilities offers an arena to small firms to increase their sustaining competitiveness. He develops different alternative models for analysing this interrelationship. This kind of theoretical development that brings entrepreneurial practices to the organizational context in small firms is still rare; even organizational entrepreneurship as a concept starts to be familiar to all of us. The contribution it can make to the future discourse at the interface of strategic management, learning organization and entrepreneurship is based on its ability to increase our understanding of the dynamic processes of entrepreneurial organizations, especially how to develop entrepreneurial practices.

Chapter 12, 'The impact of global value chains on Andalusian tourism SMEs', by the Spanish researchers Tejada and Liñán describes how the landscape of small firms in the tourism industry has changed, forcing them to adapt to the globalization process. They further argue that the competitiveness of small firms in tourism, as one of the most internationalized sectors in the world economy, is dependent on their integration into the global tourism value chain. By analysing this dynamics in seven hotels and travel agencies in the region of Andalusia the authors anticipate that these global value chains will offer an opportunity for competitiveness of small firms in the future.

Chapter 13, 'Family business responsible ownership: challenging the next generation's abilities', written by Kansikas, Krejci and Hanzelková concludes the book by bringing us ideas about how the next generation of responsible ownership could be developed. This kind of ideological discussion is very much needed to promote research in this field. It reminds us that, after all, to approach entrepreneurship as a dynamics between environment and education is impossible unless we are ready to reveal those values we believe can help the next generation to survive and enhance democracy and equality in the global landscape where the challenges are more complex than perhaps ever before. 


\section{CONCLUDING COMMENTS}

All these chapters reflect how the European landscape of entrepreneurship research is now more complex than ever. Together they represent an overview of the current state of entrepreneurship research in Europe and, we hope, also reflect the future directions of research in this field. Even if it is rooted in Europe it views and positions itself in the global context. It also appears to gather around two dimensions; on the one hand it rather contextualizes than isolates research settings and on the other hand, more than before, it views entrepreneurship as a dynamic learning and developmental process, whatever context it takes place in. These developments point out the need for comparative research settings and methodological advance to gain access to the dynamic processes of these settings, examples of which are also introduced in this book. The third branch of research, still in its nascent phase, focuses on the ideological dialogue of entrepreneurship and expands its scope from business to society. This direction actually returns to the historical roots of entrepreneurship in Europe, which originates from the ideas of the Enlightenment. These roots draw on the ideal of democracy and equal opportunity in Europe, providing educational systems for enhancing these ideals. Whether any of these three research orientations will be more powerful than others in understanding the dynamics of entrepreneurship in the future or whether this complexity will even expand is the question that inspires us to continue this European dialogue. Perhaps this complexity is actually characteristic of the European view on entrepreneurship research and thus might even strengthen in the future. We hope the reader will find these questions as inspiring as they are to us and thus feels encouraged to continue the dialogue.

\section{REFERENCES}

Bjerke, B. and T. Dalhammar (2006), 'Public entrepreneurship - Definitely different', paper presented at the UIC Research Symposium, Chicago, 2-4 August 2006.

Bobbitt, F. (2004), 'Scientific method in curriculum making', in D.J. Flinders and S.J. Thornton (eds), The Curriculum Studies Reader, second edn, New York: Routledge Falmer, pp. 9-16.

Bowen, J. (1981), A History of Western Education, Vol. 3: The Modern West, Europe and the New World, London: Methuen \& Co. Ltd.

Commission of the European Communities (2006), 'Communication from the Commission to the Council, the European Parliament, the European Economic and Social Committee and the Committee of the Regions. Putting knowledge into practice', Com (2006) 502 final, Brussels.

European Commission (2002), 'Final report of the expert group "Best Procedure" project on education and training for entrepreneurship, Enterprise Directorate General. 
European Commission (2004), 'Final report of the expert group "Education for Enterpreneurship" making progress in promoting entrepreneurial attitudes and skills through primary and secondary education', Enterprise Directorate General.

European Commission (2007), 'Entrepreneurship survey of the EU (25 member states), United States, Iceland and Norway', Analytical Report, April 2007, Flash Eurobarometer No. 192.

Fayolle, A. and O. Basso (forthcoming), 'Entrepreneurial spirit and corporate entrepreneurship in large companies', International Journal of Entrepreneurship and Small Business.

Fayolle, A., J. Uljin and P. Kyrö (eds) (2005), Entrepreneurship Research in Europe: Perspectives and Outcomes, Cheltenham, UK and Northampton, MA, USA: Edward Elgar.

Flouris, G. and G. Pasias (2003), 'A critical appraisal of curriculum reform in Greece (1980-2002), trends, challenges, and perspectives', European Education, 35(3), 73-90.

Grilo, I. and R. Thurik (2006), 'Entrepreneurship in the old and new Europe', SCALES-paper N200516, Zoetermeeter, January, 2006.

Hofstede, G.H. (2001), Culture's Consequences: Comparing Values, Behaviors, Institutions and Organizations across Nations, London: Sage Publications.

Kyrö, P. (2006) 'The continental and Anglo-american approaches to entrepreneurship education: differences and bridges', in A. Fayolle and H. Klandt (eds), International Entrepreneurship Education, Issues and Newness, Cheltenham, UK and Northampton, MA, USA: Edward Elgar, pp. 93-111.

Kyrö, P. and C. Carrier (eds) (2005), 'Entrepreneurial learning in universities: bridges across borders', in The Dynamics of Learning Entreprenurship in a CrossCultural University Context, Entreprenurship Education Series 2/2005, University of Tampere, Faculty of Education, Research Centre for Vocational and Professional Education: Saarijärven Offset, pp. 14-43.

Scott, J. and Marshall, G. (2005), A Dictionary of Sociology, Oxford: Oxford University Press, Oxford Reference Online, Oxford University Press, Malmo högskola, 16 November 2007, available at: http://www.oxfordreference.com/ views/ENTRY.html?subview=Main\&entry=t88.e242.

Stevenson, H.H. and J. Jarillo (1990), 'A paradigm of entrepreneurship: entrepreneurial management', Strategic Management Journal, 11, pp. 17-27.

Wang Xingsun (2007), 'Entrepreneurship education in Chinese universities. The challenges and opportunities', Shanghai Association of Promoting Employment of College Graduates (SAPECG), paper presented in the 2007 International Entrepreneurship Educators Conference, 10-12 September, University of Cambridge. 